\title{
Cam elyaf file ile güçlendirilen tabakalı kaplama kerestenin (TKK) bazı mekanik özellikleri üzerine bir araştırma
}

\author{
Bekir Cihad Bal*iD
}

$\ddot{O} z$

Yapısal kompozit kerestelerin, masif ağaç malzemeye göre üstün bazı özellikleri bulunmaktadır. Kusurlarından arındırılmış, daha güçlü bir malzeme olması, daha büyük ölçülerde temin edilebilmesi bu üstün özelliklerinden bazılarıdır. Özellikle son yıllarda daha güçlü yapısal kompozit keresteler elde edebilmek için farklı bilimsel çalışmalar yapılmaktadır. Bu çalışmada, kavak soyma kaplamaları ve cam elyaf file ile beraber PVA tutkalı kullanılarak tabakalı kaplama kereste üretilmiştir. Bir kontrol grubu ve 3 deney grubu oluşturulmuştur. Deney gruplarında 2, 4 ve 6 tutkal tabakasına cam elyaf file yerleştirilmiştir. Her bir grup için 4 levha üretilmiştir. Üretilen levhaların, eğilme direnci, elastikiyet modülü, vida tutma direnci, yarılma direnci ve bu testlerin sonunda elde edilen maksimum deformasyon miktarı araştırılmıştır. Elde edilen verilere göre; kontrol grubuna göre, 6 cam elyaf file kullanılan levhaların eğilme direncinde ve yarılma direncinde önemli derecede bir artış sağlandığı diğer gruplarda meydana gelen artışın istatistiksel olarak önemsiz olduğu belirlenmiştir. Mekanik özelliklerle ilgili yapılan tüm testlerde cam elyaf file ile yapılan güçlendirmenin, maksimum deformasyon miktarına pozitif yönde etki ettiği tespit edilmiştir. $\mathrm{Bu}$ artışın özelikle vida tutma direnci ve yarılma direncinde önemli seviyede olduğu belirlenmiştir.

Anahtar kelimeler: Tabakalı kaplama kereste, güçlendirme, kavak kaplama, cam elyaf file

\section{Research on some mechanical properties of laminated veneer lumber (LVL) strengthened with glass fiber net}

\begin{abstract}
Structural composite lumbers (SCLs) have some superior properties compared to solid wood material. Being free from defects, stronger material, and available in larger sizes are some of these superior features. Especially in recent years, different scientific studies have been carried out to obtain stronger structural composite timbers. In this study, laminated veneer lumber was produced using PVA adhesive together with poplar rotary-peeled veneers and glass fiber net. One control group and 3 experimental groups were formed. Glass fiber net was placed in 2, 4 and 6 glue layers in the experimental groups. Four boards were produced for each group. Flexural strength, modulus of elasticity, screw holding resistance, splitting resistance and the maximum amount of deformation obtained at the end of these tests were investigated. According to the data obtained; compared to the control group, it was determined that there was a significant increase in the flexural strength and splitting strength of the boards used 6 glass fiber mesh, and the increase in the other groups was statistically insignificant. In all tests on mechanical properties, it was determined that the reinforcement with glass fiber mesh had a positive effect on the maximum amount of deformation. It was determined that this increase was especially significant in screw holding strength and splitting strength.
\end{abstract}

Keywords: Laminated veneer lumber, strengthening, poplar veneer, glass fiber net

Makale tarihçesi: Geliș:24.10.2021, Kabül:20.11.2021, Yayınlanma:27.12.2021, *e-posta: bcbal@ hotmail.com, "Kahramanmaraş Sütçü İmam Üniversitesi, Teknik Bilimler MYO, Malzeme Bölümü, Kahramanmaraş/Türkiye, Atıf: Bal B.C., (2021), Cam elyaf file ile güçlendirilen tabakalı kaplama kerestenin (TKK) bazı mekanik özellikleri üzerine bir araştırma, Mobilya ve Ahşap Malzeme Araştırmaları Dergisi, 4 (2), 174-182, DOI:10.33725/ mamad.1014198 


\section{Giriş}

Tabakalı kaplama kereste (TKK), paralel şerit kereste (PŞK) ve lamine şerit kereste (LŞK) gibi yapısal kompozit keresteler (YKK), üstün mekanik özelliklerinden dolayı masif ahşap yerine tercih edilmektedir. TKK, bir inşaat malzemesi olarak yaygın olarak üretilmekte ve kullanılmakta ve bu malzemenin üretiminde birçok farklı ağaç türü değerlendirilmektedir (Ozarska 1999). TKK yapısal kompozit keresteler içinde en çok üretilen ve kullanılandır. İngilizce "Laminated Veneer Lumber" olarak bilinmekte ve LVL olarak kısaltılarak kullanılmaktadır. Bu çalışmada bu noktadan sonra orijinal adına sadık kalınarak LVL olarak anılacaktır.

LVL'nin masif ahşapla karşılaştırıldığında birçok avantajı vardır. LVL masif ağaç malzemede bulunan doğal odun kusurlardan büyük oranda arındırılmıştır. Yoğunluğu ve mekanik özellikleri üretildiği odun türününkinden daha yüksektir. Masif ağaç malzemede elde edilemeyecek ölçüler, LVL'de üretilebilmektedir (Neuvonen ve ark. 1998; Bao ve ark. 2001; Burdurlu ve ark. 2007; Shukla ve Kamdem, 2009; Bal ve ark., 2013).

Lamine ahşap malzemelerin daha yüksek mekanik özellikler kazanabilmesi için güçlendirilmesi üzerine bilimsel çalışmalar yapılmıştır. Güçlendirme çalışmaları ilk olarak Wangaard (1964) ve Biblis (1965) tarafından yapılmıştır. Her iki araştırmacıda bu ilk denemelerde değişik türdeki masif ahşap malzeme üzerine epoksi reçine ile muamele edilmiş cam elyaf kullanarak denemeler yapmışlardır. Bir başka çalışmada E-glass ve S-glass sınıfı cam elyaf, kevlar, Grafit gibi bazı sentetik liflerle güçlendirmenin ekonomik fizibilitesi Laufenberg ve ark. (1984) tarafından araştırılmıştır. Bu çalışma sonucunda, en az maliyetli olan güçlendirmenin E-glass cam elyafı ile ve fenol formaldehit kullanarak gerçekleşebileceği rapor edilmiştir. Basterra ve ark. (2012) tarafından yapılan bir çalışmada, I-214 kavak klonu ile üretilen kavak kirişlerin bazı mekanik özellikleri incelenmiştir. Güçlendirmede cam elyaf dokuma, carbon elyaf dokuma ve keten elyaf dokuma kullanılmıştır. Yapılan testler sonucunda sadece karbon elyafi ile yapılan güçlendirmedeki farklılıklar istatistiksel olarak önemli bulunmuştur. Ribeiro ve ark. (2009) Maritime çamından elde edilen tutkallanmış lamine ahşap kirişlerin cam elyaf ve pultruzyon levha güçlendirilmesi üzerine bir çalışma yapmışlar ve çalışmadan elde edilen verilere göre; cam elyaf ile güçlendirmenin test örneklerinin elastikiyet modülü üzerine istatistiksel olarak etkili olmadığını belirlemişlerdir. Rowland ve ark. (1986) 10 farklı tutkal türü ve birçok farklı formdaki cam elyaf, grafit elyaf ve Kevlar ile akça ağaçtan elde edilen lamine ahşap malzeme üzerinde denemeler yapmışlardır. Elde edilen verilere göre, en başarılı tutkal türü epoksi ve güçlendirme için en uygun elyafın cam elyaf olduğunu belirtmişlerdir. Kavak LVL malzemenin güçlendirilmesine dair çalışmalar Bal ve Özyurt (2015), Bal (2014) Bal (2017) tarafından farklı kombinasyonlar da üretilen malzeme üzerinde yapılmıştır. Yapılan bu çalışmalar sonunda elde edilen verilere göre; cam elyaf ile güçlendirilen LVL malzemenin eğilme direnci ve elastikiyet modülü değerlerinde, cam elyaf desteğinin çekme bölgesine yapıştırıldığı test örneklerinde önemli bir artışa sebep olduğu belirlenmiştir. Ancak, cam elyaf dokuma ile güçlendirilen test örneklerinin ağırlık artışının fazla olduğu bu nedenle, test örneklerinin mekanik özelliklerinin yoğunluğa bölünerek spesifik mekanik özelliklerin elde edildiği rapor edilmiştir. Bu spesifik mekanik özelliklere göre cam elyaf dokuma ile güçlendirme işleminin kavaktan üretilen LVL malzemede çok önemli seviyelerde mekanik performans artışına sebep olmadığ 1 sonucuna varılmıştır. Yukarıda verilen önceki çalışmalarda, cam elyaf desteği ya çekme bölgesine ya da tutkal tabakalarına yerleştirilmiştir ve sıcakta sertleşen tutkallar kullanılmıştır.

Bu çalışmanın amacı, oda şartlarında sertleşen tutkallar kullanarak, cam elyaf file desteği ile üretilen kavak lamine malzemenin mekanik özelliklerinin araştırılmasıdır. 


\section{Materyal ve Metot}

\subsection{Materyal}

Çalışmada kavak (Populus subspecies) odunundan elde edilen 2,8 2 mm kalınlıkta ve 60x60 cm genişlik ve uzunlukta olan soyma kaplamalar kullanılmıştır. Bu ölçülerdeki 7 adet soyma kaplama levhası seçilmiş bu taslak Şekil 1'de görüldüğü gibi 4 parçaya bölünmüştür. Elde edilen 30x30 cm ölçülerindeki levha taslaklarının her biri bir gruba dahil edilmiştir. $\mathrm{Bu}$ şekilde 4 tekrar ve toplamda 16 levha oluşturulmuştur.

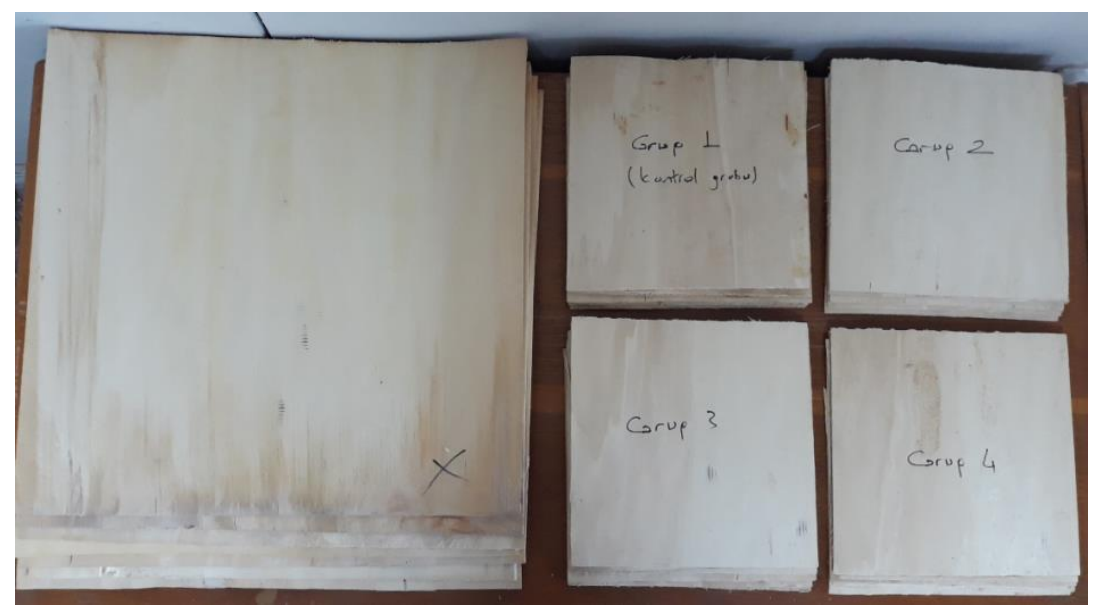

Şekil 1. Soyma kaplamalardan levha taslaklarının oluşturulması

Kaplama levhalarının yapıştırılmasında PVA tutkalı kullanılmıştır. Tutkalın görünümü sıv1 emülsiyon, pH değeri 3.5-5, viskozitesi 20.000-4.000 mPa.s, yoğunluğu $1.055 \mathrm{~g} / \mathrm{cm}^{3}$, katı madde miktarı \%52 \pm 2 'dir. Tutkal kaplama levhalarına yaklaşık olarak $230 \pm 20$ gram olacak şekilde ve firça ile sürülmüştür. Tutkallanan kaplama levhaları üst üste yerleştirilirken kontrol grubunda (grup 1) cam elyaf file kullanılmamıştır. Kullanılan cam elyaf file $160 \mathrm{gr} / \mathrm{m}^{2}$, ağırlıkta, alkali dayanımlı, $4 \times 4 \mathrm{~mm}$ gözenekli yapıda ve turuncu renktedir. Grup 2, grup 3 ve grup 4 için üretilen levhalara sırasıyla 2,4 ve 6 adet cam elyaf file yerleştirilmiştir. $\mathrm{Bu}$ levhaların şematik görüntüsü aşağıda Şekil 1'de verilmiştir. Bu şekilde oluşturulan levha taslakları oda şartlarında preslenmiştir. Presleme işleminde; pres basıncı $6 \pm 0.5 \mathrm{~kg} / \mathrm{cm}^{2}$ ve pres süresi 4 saat olarak ayarlanmıştır (soğuk presleme). Preslenen levhalar oda şartlarında 1 hafta süre ile bekletilmiş ve sonra test örnekleri hazırlanmıştır.

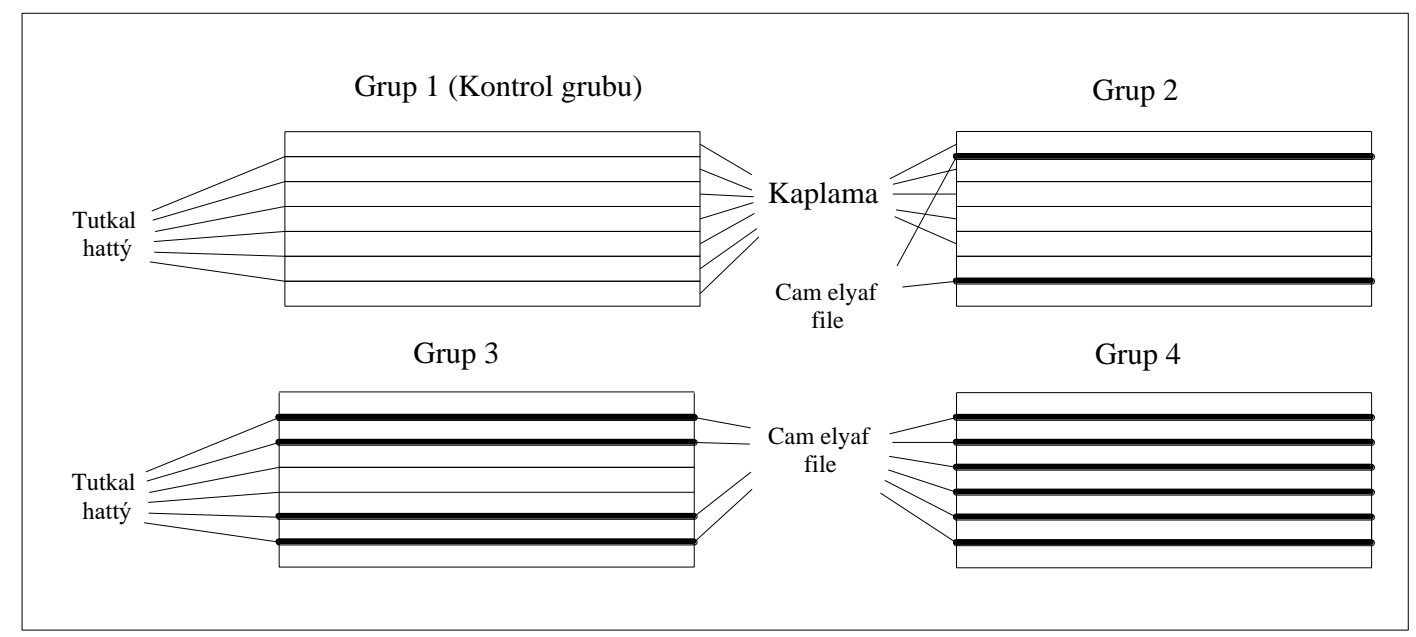

Şekil 2. Kontrol grubu ve deney grubu test örneklerinin tabaka organizasyonu 


\subsection{Metot}

LVL test örnekleri masif ağaç malzemeye yakın özellikler göstermesi nedeniyle, masif ağaç malzemenin, yoğunluğunun, eğilme direncinin ve elastikiyet modülünün tespit edilmesinde kullanılan TS 2472, TS 2474 ve TS 2478 numaralı standartlara göre yapılmıştır. Eğilme direnci test örnekleri levha kalınlığında, $2 \mathrm{~cm}$ genişliğinde ve $30 \mathrm{~cm}$ uzunluğunda kesilip hazırlanmıştır. Her bir levhadan 4 adet ve toplamda 16 adet test örneği hazırlanmıştır. Eğilme direnci testleri Şekil 3-A'da görülen, 1 ton kapasiteli elektromekanik prensible çalışan bir test cihazında yapılmıştır. Eğilme direnci testi yapılırken kuvvet test örneğinin yan yüzeyine, tutkal hattına paralel yönde uygulanmıştır. Test hızı $10 \mathrm{~mm} / \mathrm{dk}$, mesnetler arası açıklık $24 \mathrm{~cm}$, ön yük miktarı $100 \mathrm{~N}$, test sonu ise maksimum kuvvetin \%70'i olarak ayarlanmıştır. Bu deney hızı ile en büyük kuvvete yaklaşık olarak $60 \pm 20$ saniye sonunda ulaşılmıştır.

Vida tutma direncinin hesaplanmasinda TS EN 13446 numaralı standartta belirtilen esaslara uyulmuştur. Test örnekleri levha kalınlığında ve 50x50 mm ölçülerinde kare kesitli olarak hazırlanmıştır. Denemelerde 4x50 mm ölçülerinde çinko vidalar kullanılmıştır. Vidalar test örneğinin yüzeyine ve orta noktasına vidalanmıştır. Vidalar test örneğinin kalınlığı kadar vidalanmıştır. Vida tutma direnci testleri yapılırken ön yük değeri $100 \mathrm{~N}$, test hızı $10 \mathrm{~mm} / \mathrm{dk}$, test sonu ise maksimum kuvvetin \%80'i olarak ayarlanmıştır. Vida tutma direnci testinin yapılmasına dair bir görüntü Şekil 3-B'de verilmiştir.

Yarılma direncinin hesaplanmasında TS 7613 numaralı standartta belirtilen esaslara uyulmuştur. Test örnekleri levha kalınlığında ve 50x50 mm ölçülerinde kare kesitli olarak hazırlanmıştır. Test örneklerinin bir kenarına, yarılma direnci testi için kullanılan başlığın takılabilmesi için $22 \mathrm{~mm}$ çapında bir delik delinmiştir. Yarılma direnci testleri yapılırken ön yük değeri $100 \mathrm{~N}$, test hızı $10 \mathrm{~mm} / \mathrm{dk}$, test sonu ise maksimum kuvvetin \%80'i olarak ayarlanmıştır. Yarılma direnci testinin yapılmasına dair bir görüntü Şekil 3-C'de verilmiştir.
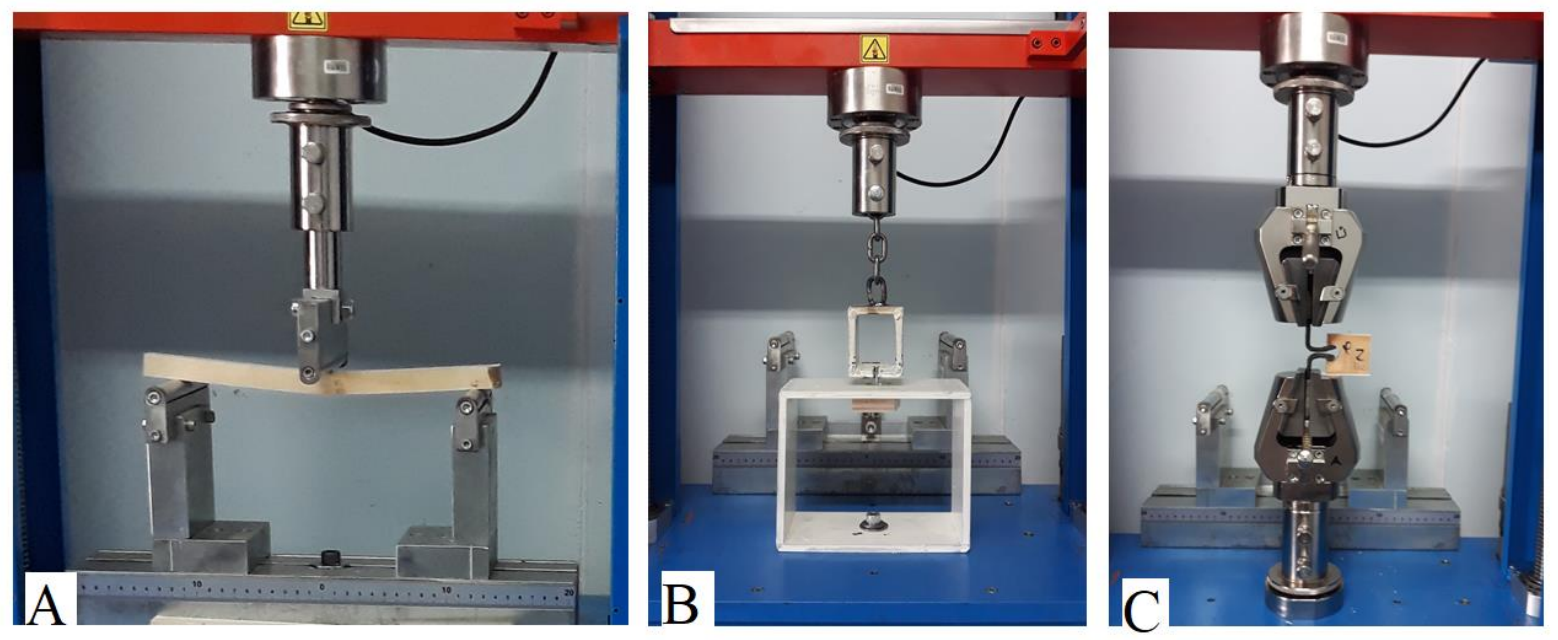

Şekil 3. Eğilme direnci (A), vida tutma direnci (B) ve yarılma direncinin (C) yapılması

\subsection{1 İstatistik hesaplamaların yapılması}

Elde edilen veriler Excel programında düzenlenmiş ve SPSS programında One-Way ANOVA testi ile gruplar arasında fark olup olmadığı belirlenmeye çalışılmıştır. Aralarında istatistiksel olarak fark belirlenen test verilerinde, Duncan testi ile hangi grupların önemli derecede birbirlerinden farklılık gösterdiği belirlenmiştir. 


\section{Bulgular ve Tartışma}

Denemeler sonunda elde edilen mekanik özelliklere ait testlerden elde edilen veriler ve maksimum deformasyon değerleri Tablo 1'de verilmiştir. Tabloda verilen veriler incelendiğinde eğilme direnci, kontrol grubunda (grup 1) $58,9 \mathrm{~N} / \mathrm{mm}^{2}, 6$ adet cam elyaf filenin kullanıldığ 1 grup 4 'de ise $66.8 \mathrm{~N} / \mathrm{mm}^{2}$ olarak elde edilmiştir. Kontrol grubu ile grup 4 arasındaki fark istatistiksel olarak ileri düzeyde önemlidir $(\mathrm{P}<0.01)$. Kontrol grubu ile grup 2 ve grup 3 arasında fark istatistiksel olarak önemsizdir (NS). Çalışmadan elde edilen bu verilere göre, kavak soyma kaplamaları ile üretilen 7 tabakalı LVL levhalarda, 2 veya 4 adet cam elyaf file ile yapılan güçlendirmenin, üretilen LVL levhaların eğilme direncini bir miktar artırdığı ancak istatistiksel olarak önemli bir katkısının olmadığı görülmektedir. Eğilme direnci testleri test örneğinin yan yüzeyi üzerinde yapılmıştır. Kuvvet tutkal hattına paralel şekilde uygulanmıştır. $\mathrm{Bu}$ şekilde yapılan eğilme direnci testlerinde, LVL test örneğini oluşturan tüm kaplama levhalarına ve aynı zamanda tutkal hattına bırakılan güçlendirme malzemelerinin tamamına aynı anda kuvvet uygulanmaktadır. Eğer testler üst yüzey üzerine kuvvet uygulanarak yapılsa, bu durumda ilk etkilenen kaplama levhaları en alt tabakada (çekme yüzeyi) bulunan kaplama levhaları olurdu. Bu nedenle, yan yüzey üzerinde yapılan eğilme direnci denemelerinde hem LVL test örneğini oluşturan kaplama levhaları ve hem de güçlendirme materyali, uygulanan kuvvete toplu olarak karşı koymaktadır. Bu nedenle, yan yüzeyde yapılan eğilme direnci testleri ile üst yüzeyde yapılan eğilme direnci testlerinin sonuçları birbirlerinden farklı çıkmaktadır. Bu konuda yapılan önceki çalışmalarda bu durum rapor edilmiştir (Bao ve ark., 2001; Bal 2014; Karaman ve ark., 2021; Yıldırım ve ark., 2021).

Tablo 1. Testlerden elde edilen veriler, ANOVA ve Duncan testi sonuçları

\begin{tabular}{|c|c|c|c|c|c|c|c|c|c|c|c|}
\hline \multirow{2}{*}{ Test } & \multirow{2}{*}{ İD } & \multicolumn{4}{|c|}{$\begin{array}{l}\text { Mekanik özelliklere ait test verileri } \\
\qquad\left(\mathrm{N} / \mathrm{mm}^{2}\right)\end{array}$} & \multirow{2}{*}{$\begin{array}{l}\text { ANOVA } \\
\text { P değeri }\end{array}$} & \multicolumn{4}{|c|}{$\begin{array}{l}\text { Maksimum deformasyon verileri } \\
(\mathrm{mm})\end{array}$} & \multirow{2}{*}{$\frac{\text { ANOVA }}{\text { P değeri }}$} \\
\hline & & Grup 1 & Grup 2 & Grup 3 & Grup 4 & & Grup 1 & Grup 2 & Grup 3 & Grup 4 & \\
\hline \multirow{2}{*}{$\sigma$} & $\mathrm{x}$ & $58.9 \mathrm{~A}$ & $59.6 \mathrm{~A}$ & $61.8 \mathrm{~A}$ & $66.8 \mathrm{~B}$ & $\mathrm{P}<0.01$ & $9.8 \mathrm{~A}$ & $10.1 \mathrm{~A}$ & $10.8 \mathrm{~A}$ & $11.2 \mathrm{~A}$ & $\begin{array}{c}\mathrm{P}>0.05 \\
(\mathrm{NS})\end{array}$ \\
\hline & ss & 5.99 & 7.05 & 7.18 & 4.35 & & 2.07 & 1.97 & 1.78 & 1.73 & \\
\hline \multirow{2}{*}{ E } & $\mathrm{x}$ & $5355 \mathrm{~A}$ & $5448 \mathrm{~A}$ & $5507 \mathrm{~A}$ & $5783 \mathrm{~A}$ & $\begin{array}{c}\mathrm{P}>0.05 \\
(\mathrm{NS})\end{array}$ & - & - & - & - & \\
\hline & ss & 596 & 609 & 639 & 536 & & - & - & - & - & \\
\hline \multirow{2}{*}{$f_{v t}$} & $\mathrm{x}$ & $26.9 \mathrm{~A}$ & $28.1 \mathrm{~A}$ & $28.2 \mathrm{~A}$ & $28.3 \mathrm{~A}$ & $\begin{array}{c}\mathrm{P}>0.05 \\
(\mathrm{NS})\end{array}$ & $2.2 \mathrm{~A}$ & $2.5 \mathrm{~B}$ & $2.9 \mathrm{C}$ & $3.0 \mathrm{C}$ & $\mathrm{P}<0.001$ \\
\hline & ss & 4.37 & 3.11 & 3.23 & 3.37 & & 0.28 & 0.24 & 0.34 & 0.34 & \\
\hline \multirow{2}{*}{$f_{y}$} & $\mathrm{x}$ & $0.65 \mathrm{~A}$ & $0.98 \mathrm{~B}$ & $1.37 \mathrm{C}$ & $1.68 \mathrm{D}$ & $\mathrm{P}<0.001$ & $2.75 \mathrm{~A}$ & $3.53 \mathrm{~B}$ & $5.40 \mathrm{C}$ & $7.23 \mathrm{D}$ & $\mathrm{P}<0.001$ \\
\hline & ss & 0.16 & 0.11 & 0.15 & 0.16 & & 0.70 & 0.45 & 0.77 & 0.99 & \\
\hline \multirow{2}{*}{$\mathrm{D}$} & $\mathrm{x}$ & $484 \mathrm{~A}$ & $490 \mathrm{AB}$ & $516 \mathrm{BC}$ & $518 \mathrm{C}$ & $\mathrm{P}<0.01$ & & & & & \\
\hline & SS & 39 & 38 & 27 & 40 & & & & & & \\
\hline
\end{tabular}

ID: istatistik değer, x:aritmetik ortalama, ss: standart sapma, $\sigma$ : eğilme direnci, $E$ : elastikiyet modülü, $f_{v i}$ : vida tutma direnci, $f_{y}$ : yarılma direnci

Eğilme direnci testi esnasında ölçülen eğilmede elastikiyet modülü verileri incelendiğinde, eğilme direnci verilerine benzer sonuçlar elde edildiği görülmektedir. Kontrol grubu ile deney grubu test örnekleri arasında (grup 2, grup 3 ve grup 4) farklar olduğu, cam elyaf file sayısı arttıkça eğilmede elastikiyet modülü değerinin arttığı, ancak, gruplar arasında istatistiksel olarak önemli bir farklılık olmadığı tespit edilmemiştir (NS). Bunun olası sebebinin, tutkal tabakasında kullanılan cam elyaf file desteğinin, kavak kaplamalardan daha 
esnek bir malzeme olması, daha kolay eğilip büküle bilmesi, ancak buna karşın, çekme direncinin daha yüksek olmasıdır. Eğilme direnci testi esnasında, test başladıktan sonra, test örneğinin alt orta noktasında, alt yüzeyine yakın bölgelerde mesnet noktalarına doğru bir çekme kuvveti oluşmaktadır. Bunun bir sonucu olarak, cam elyaf desteği fazla olan gruplarda, elastikiyet modülü değeri biraz daha yüksek ölçülmektedir. Ancak, gruplar arasında önemli bir farklılık tespit edilememiştir. Daha önce yapılan bir çok çalışmada, cam elyaf dokuma kumaş veya diğer güçlendirme malzemeleri kullanılarak yapılan çalışmalarda, test örneğinin alt yüzeyine yapıştırılan veya ara tutkal tabakasında kullanılan güçlendirme malzemelerinin eğilmede elastikiyet modülü değerini artırdığı tespit edilmiştir (Biblis, ve Carino 2000; Bal ve ark., 2015; Bal ve Özyurt 2015). Ancak, bu çalışmalarda elde edilen sonuçların aksine, Ribeiro ve ark. (2009) tarafından yapılan çalışmada; Maritime çamından elde edilen tutkallanmış lamine ahşap kirişlerin cam elyaf ile güçlendirilmesinin test örneklerinin elastikiyet modülü üzerine istatistiksel olarak etkili olmadığını belirlemişlerdir. Basterra ve ark. (2012) tarafından yapılan bir çalışmada, I-214 kavak klonu ile üretilen kavak kirişlerin bazı mekanik özellikleri incelenmiştir. Güçlendirmede cam elyaf dokuma, karbon elyaf dokuma ve keten elyaf dokuma kullanılmıştır. Yapılan testler sonucunda sadece karbon elyafı ile yapılan güçlendirmedeki farkl1lıklar istatistiksel olarak önemli bulunmuştur. Cam elyaf ile yapılan güçlendirmenin eğilme direnci ve eğilmede elastikiyet modülünü artırıcı bir etkisi belirlenmemiştir.

Eğilme direnci testi sonunda elde edilen verilerden biriside maksimum deformasyon miktarıdır. Eğilme direnci testinde, test esnasında, test örneğinin uygulanan kuvvete karşı maksimum karşı koyma yüküne (Fmax) ulaşıldıktan sonra, test örneğinin tokluk özelliği olarak, testin son bulması değişiklik göstermektedir. Bazı ahşap malzemelerde maksimum yüke ulaştıktan sonra test örneği ani olarak kırılmakta ve test tamamlanmaktadır. Bu türden malzemeler gevrek malzeme olarak anılmaktadır. Bazı malzemelerde ise maksimum yüke ulaştıktan sonra test örneği yavaş yavaş veya kademeli bir şekilde kırılmakta ve test tamamlanmaktadır. Bu türden malzemeler ise elastik (esnek) malzeme olarak anılmaktadır. Eğilme direnci testi esnasında, oluşturulan yük-deformasyon grafiği altında kalan alan ne kadar büyükse malzeme o kadar esnek ve bu alan ne kadar küçükse malzeme o kadar gevrek malzeme olarak tanımlanmaktadır. Yapılarda, LVL gibi yük taşıyan yapısal elemanların, büyük yükleri taşıyabilmesi ve esnek bir yapıya sahip olması istenmektedir. Bu nedenle, bu çalışmada elde edilen veriler önem arz etmektedir. Her ne kadar grup 2 ve grup 3 te elde edilen eğilme direnci verileri kontrol grubuna göre yeterince yüksek değilse de, bu test esnasında elde edilen maksimum deformasyon değerlerinde gözlenen artış, istatistiksel olarak önemsiz (NS) olsa bile, bu çalışmanın sonunda elde edilen önemli bir sonuç olarak değerlendirilmiştir. Bu sonuca benzer bir sonuç Bal ve ark. (2015) tarafindan, cam elyaf dokuma kumaş ile güçlendirilen kontrplağın eğilme direnci testi sonucunda da rapor edilmiştir. Bu çalışma ile yapılan önceki çalışmalar arasındaki önemli farklılıklardan bazıları; güçlendirme malzemesinin dokuma özelliği, güçlendirme malzemesinin gramajı, güçlendirme malzemesinin tabakalı ahşap malzemede uygulandığı yer, kullanılan tutkal türü, pres basıncı, pres sıcaklığıdır. Yapılan önceki çalışmalarla, bu şekilde farklılıklar varken, elde edilen sonuçlarında farklılık göstermesi beklenen bir sonuç olarak yorumlanmıştır.

Yapılan çalışma sonunda elde edilen vida tutma direnci testlerine ait veriler yukarıda Tablo 1'de verilmiştir. Bu veriler incelendiğinde, vida tutma direnci değerleri arasında küçük farklar olduğu, cam elyaf file ile desteklenen deney grubu test örneklerinin biraz daha yüksek değerler verdiği görülmektedir. Ancak, gruplar arasındaki farklar istatistiksel olarak önemsizdir (NS). Bu konuda yapılan bir önceki çalışmada, Bal (2017) tarafından, cam elyaf dokuma ile güçlendirilen kontrplağın vida tutma direnci, vida başı tutma direnci ve yanal vida tutma direnci araştırılmış ve genel olarak bu dirençlerde bir artış olduğu rapor edilmiştir. 
Önceki çalışma ile sunulan bu çalışma arasında bu şekilde farklı sonuçlar elde edilmesinin temel nedeni, kullanılan güçlendirme malzemesinin farklı olmasıdır. Yapılan bu çalışmada kullanılan cam elyaf file gözenekli yapıda olan bir malzemedir ve gramaj1 $150 \mathrm{gr} / \mathrm{m}^{2}$ dir. Yapılan önceki çalışmada ise gramaj1 $500 \mathrm{gr} / \mathrm{m}^{2}$, dir. Vida tutma direnci testi sonucunda elde edilen bir diğer veri ise maksimum deformasyon miktarıdır. Kontrol grubu ile kıyaslandığında, deney grubu test örneklerinden elde edilen maksimum deformasyon miktarları cam elyaf file sayısı arttıkça artmıştır. Bu sonucun, vida tutma direnci testi sonucunda elde edilen önemli bir sonuç olduğu söylenebilir.

Tablo 1'de verilen bir diğer test ise yarılma direnci testidir. Yarılma direnci testi verileri incelendiğinde, kontrol grubuna göre deney grubu test örneklerindeki artışın her grupta istatistiksel olarak çok ileri düzeyde önemli $(\mathrm{P}<0.001)$ olduğu belirlenmiştir. $\mathrm{Bu}$ çalışmada sunulan mekanik özellikler içerisinde, cam elyaf file desteğinin en önemli etkisi yarılma direncinde elde edilmiştir. Bunun en önemli sebebinin, yarılma direnci testi esnasında, LVL levhayı oluşturan kaplama levhaları yarılma direncine maruz kalırken, tutkal tabakası içinde yer alan cam elyaf file tabakaları ise çekme direncine maruz kalmaktadır. Ahşap malzemenin yarılma direnci, cam elyaf filenin çekme direncine göre çok daha küçüktür. Bu nedenle, bu çalışmada testleri yapılan cam elyaf file ile güçlendirilmiş olan deney grubu test örneklerinin yarılma direnci kontrol grubuna göre çok daha büyük ölçülmüştür. Yarılma direnci testi esnasında, deney grubu test örneklerinden elde edilen maksimum deformasyon miktarları da, kontrol grubu ile kıyaslandığında, aradaki farkların istatistiksel olarak çok ileri düzeyde $(\mathrm{P}<0.001)$ önemli olduğu belirlenmiştir. Bu durumun özellikle bağlantı noktalarında, LVL malzemenin uç kısımlarında çivi ya da vida ile yapılan bağlantılarda, zorlanmalar karşısında yarılması sorununa bir çözüm olabileceği söylenebilir.

\section{Sonuçlar ve Öneriler}

$\mathrm{Bu}$ çalışmada, kavak soyma kaplamaları ve cam elyaf file ile beraber PVA tutkalı kullanılarak tabakalı kaplama kereste üretilmiştir. Üretilen levhaların bazı mekanik özellikleri belirlenmiş ve kontrol grubu ile deney grubu test örnekleri arasındaki farklılıklar araştırılmıştır. Elde edilen verilere göre;

- Eğilme direnci verilerinde, sadece kontrol grubu ile grup 4'e ait test örnekleri arasında istatistiksel olarak önemli bir farklılık elde edilmiştir.

- Elastikiyet modülü verilerine göre, kontrol grubu ile deney grubu verileri arasında istatistiksel olarak önemli bir farklılık belirlenmemiştir.

- Vida tutma direnci verilerinde, kontrol grubu ile deney grubu verileri arasında önemli bir farklılık yoktur, ancak, maksimum deformasyon verileri arasında vardir.

- Yarılma direnci verilerinde, kontrol grubu ile deney grubu verileri arasında çok ileri düzeyde önemli farklılıklar belirlenmiştir. Ayrıca, yarılda direnci testi sonunda elde edilen maksimum deformasyon verileri arasında da aynı derecede farkl1lıklar tespit edilmiştir.

\section{Teşekkür}

Bu çalışma Kahramanmaraş Sütçü İmam Üniversitesi araştırma projeleri yönetim birimi başkanlığı tarafından desteklenmiştir. Proje numarası: 2021/1-36 M. Bu desteğinden dolayı KSÜ-BAP birimine teşekkür ediyoruz. 


\section{Kaynaklar}

Bal. B.C., Özdemir, F., Altuntaş E, (2013), Masif ağaç malzeme ve tabakalı kaplama kerestenin vida tutma direnci üzerine karşılaştırmalı bir çalışma, Düzce Üniversitesi Ormancilık Dergisi, 9(2),14-22.

Bal. B.C., (2014), Flexural properties, bonding performance and splitting strength of LVL reinforced with woven glass fiber, Construction and Building Materials, 51 (2014), 914.

Bal, B. C., Özyurt, H. (2015), Cam elyaf dokuma ile güçlendirilmiş tabakalı kaplama kerestenin bazı teknolojik özellikleri. Kahramanmaraş Sütçü İmam Üniversitesi Mühendislik Bilimler Dergisi, 18 (1), 9-16.

Bal, B. C., Bektaş, İ., Mengeloğlu, F., Karakuş, K., Demir, H. Ö. (2015), Some technological properties of poplar plywood panels reinforced with glass fiber fabric, Construction and Building Materials, 101(1), 952-957.

Bal, BC, (2017), Screw and nail holding properties of plywood panels reinforced with glass fiber fabric, Cerne, 23(1), 11-18.

Bao, F., Fu, F., Choong, T., H.S.E., C, (2001), Contribution factor of wood properties of three poplar clones to strength of laminated veneer lumber, Wood and Fiber Science, 33 (3), 345-352.

Basterra, LA, Acuna, L, Casado, M, Lopez, G, Bueno, A, (2012), Strength testing of Poplar duo beams, Populus x euramericana (Done) Guinier cv. I-214, with fibre reinforcement, Construction and Building Materials, 36 (2012), 90-96.

Biblis EJ. (1965), Analysis of wood-fiberglass composite beams within and beyond the elastic region, Forest Products Journal, 15 (2), 81-89.

Biblis, E. J., Carino, H. F. (2000), Flexural properties of southern pine plywood overlaid with fiberglass-reinforced plastic, Forest Products Journal, 50(4), 34-34.

Burdurlu, E., Kılıç, M., İlce, A.C., Uzunkavak, O., (2007), The effects of ply organization and loading direction on bending strength and modulus of elasticity in laminated veneer lumber (LVL) obtained from beech (Fagus orientalis L.) and Lombardy poplar (Populus nigra L.), Construction and Building Materials, 21: 1720-1725.

Karaman, A., Yildirim, M. N., Tor, O. (2021), Bending characteristics of laminated wood composites constructed with black pine wood and aramid fiber reinforced fabric, Wood Research, 66(2), 309-320.

Laufenberg TL, Rowlands RE, Krueger GP. (1984), Economic feasibility of synthetic fiber reinforced laminated veneer lumber (LVL), Forest Products Journal, 34 (4), 15-22.

Neuvonen, E., Salminen, M., Heiskanen, J., (1998), Laminated Veneer Lumber, Wood Based Panels Technology, Department of Forest Products Marketing.

Ozarska, B. (1999), A review of the utilization of hardwoods for LVL, Wood Science and Technology.33, 341-351.

Ribeiro AS, Jesus AMP, Lima AM, Lousada JLC, (2009), Study of strengthening solutions for glued-laminated wood beams of maritime pine wood, Construction and Building Materials, 23:2738-2745.

Rowlands RE, Deweghe RPV, Laufenberg TL, Krueger GP, (1986), Fiber-reinforced wood composites, Wood and Fiber Science, 18 (1), 39-57. 
Shukla, S.R., Kamdem, P.D. (2009), Properties of laboratory made yellow poplar (Liriodendron Tulipifera) laminated veneer lumber: effect of the adhesives, European Journal of Wood and Wood Products, 67: 397-405.

TS 2472, Odunda fiziksel ve mekaniksel deneyler için hacim yoğunluk değerinin tayini, Türk Standartları Enstitüsü, Ankara, 1976.

TS 2474, Odunun statik eğilme dayanımının tayini, Türk Standartları Enstitüsü, Ankara, 1976.

TS 2478, Odunun statik eğilmede elastiklik modülünün tayini, Türk Standartları Enstitüsü, Ankara, 1976.

TS 7613, Odunun yarılma mukavemetinin tayini, Türk Standartları Enstitüsü, Ankara, 1989.

TS EN 13446, Ahşap esaslı levhalar-Bağlayıcıların geri çıkma kapasitesinin tayini, TSEAnkara. 2005,

Wangaard FF. (1964), Elastic deflection of wood-fiberglass composite beams, Forest Products Journal, 13 (6), 256-260.

Yildrim, M. N., Karaman, A., Zor, M. (2021), Bending characteristics of laminated wood composites made of poplar wood and GFRP, Drvna industrija, 72(1), 3-11. 